\title{
Improving the Saliency of a High Speed SynRel Rotor by using High Strength Martensitic Sleeve
}

\author{
R. M. Ram Kumar ${ }^{\dagger}$, Gaurang Vakil ${ }^{\dagger}$, Antonino La Rocca ${ }^{\dagger}$, \\ David Gerada $^{\dagger}$, Chris Gerada ${ }^{\dagger}$ and B. G. Fernandes $~ ๘$ \\ $\dagger$ Power Electronics, Machines and Control Group, University of Nottingham, Nottingham NG7 2RD, U.K, \\ I Department of Electrical Engineering, Indian Institute of Technology - Bombay, Powai, Mumbai - 400076, India \\ Email: ramkumar.ramanathan@nottingham.ac.uk, gaurang.vakil@nottingham.ac.uk
}

\begin{abstract}
High strength magnetic steel laminations are the invariable choice to achieve the power density demands of high speed electric machines required in the automotive industry. However, the cost competitive automobile market, favours the use of conventional materials. Consequently, in this paper, a high strength martensitic sleeve rotor configuration is identified as an ideal choice to maximize the use of conventional materials in a high speed synchronous reluctance (SynRel) machine. A 3.5 kW, $60 \mathrm{krpm}$ high speed SynRel machine is designed for an electric assist turbocharger (EAT) to disclose the benefits of sleeve rotor configuration. The performance of the sleeve rotor is on par and superior to a SynRel machines employing high and low strength laminations respectively. Finally, a multiphysics optimization is performed to ascertain the superiority of sleeve rotor SynRel configuration. Based on this, the sleeve rotor produces $4.5 \%$ and 46.7\% more torque than the SynRel machines using high and low strength laminations with conventional rotor configurations. Additionally, this is achieved with nearly $90 \%$ by volume of conventional rotor lamination.
\end{abstract}

Index Terms-High speed, sleeve rotor, synchronous reluctance machine, torque density.

\section{INTRODUCTION}

A profound change in the power train strategy is essential to meet the stringent standards set on the tailpipe emission [1]. Electric vehicles (EVs), with zero tail pile emission, are the ideal choice to curb pollution. The global sales of internal combustion engines (ICEs) are projected to decline with the growth of EVs. Despite their decline in market share, more than $60 \%$ of the total automotive sales in 2030 is expected to be of ICEs [2]. Therefore, in addition to the promotion of $\mathrm{EVs}$, it is imperative to upgrade the power trains in ICEs.

Improved fuel economy and reduced tail pipe emission are conventionally realized by turbocharging an ICE [3]. However, turbo lag associated with the transient operations adversely effects the performance of a turbocharged ICE. Providing an electric assist, during transient operations, is one of the notable methods to reduce turbo lag [4]. This has led to the development of EATs which comprises of a turbine, compressor and an electric machine on the same shaft. High speed operation of the compressor, during transients, is mandatory to realize the benefits of incorporating a turbocharger [3]. Consequently, there is an extensive focus on the development of various high speed electric machines for the EATs [5], [6]. Harsh environment and wide temperature gradient favours the use of an induction machine [7]. SynRel machine is barely considered as a choice for EATs despite its rugged, simple and permanent magnet less configuration. Therefore, this paper is aimed at studying the applicability of a SynRel machine for an EAT.

Increased rib thickness is necessary to handle the induced stress occurring at high speed operations of a SynRel machine. This degrades the output torque capability of a high speed SynRel machine [8]. Rotor lamination with high yield strength is a potential solution to overcome the aforementioned problem. However, the use of high strength lamination makes the electric machine expensive and renders the solution to be impractical for the cost competitive automobile market. The application of retaining sleeves to provide mechanical support is currently in wide use for the high speed permanent magnet machines [9]. In contrast, SynRel machines having a retaining sleeve is at the early stages of development with minimal available literature like [10], [11]. In addition, only high strength and non magnetic materials like titanium, inconel and carbon fiber are considered for the retaining sleeve. Furthermore, the elimination of iron ribs in [10], [11] results in a rotor structure very similar to the axially laminated SynRel machine proposed in [12]. This, in turn, adds to the complexity of rotor fabrication.

SynRel rotor with a magnetic high strength retaining sleeve and supporting iron ribs is proposed in this paper. This paper is organized as follows. The specification of the SynRel machine are given in Section II. Preliminary design of the high speed SynRel rotor with high strength lamination, low strength lamination and retaining sleeve are discussed in Sections III, IV and $\mathrm{V}$, respectively. The superiority of the sleeve rotor is proved with a multiphysics optimization in Section VI. Finally, the reason behind the superior performance of the sleeve rotor and the major outcomes of this research are highlighted in Sections VII and VIII, respectively.

\section{MACHINE SPECIFICATION}

The impact of an electric assist in reducing the turbo lag is highly influenced by the torque density of the corresponding electric machine and its rotor inertia. The electric machine sizing is performed appropriately to prevent the electric assist 


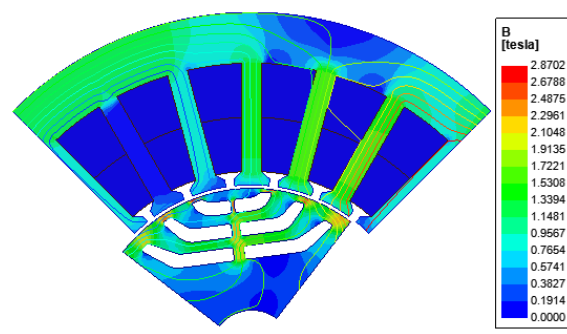

(a)

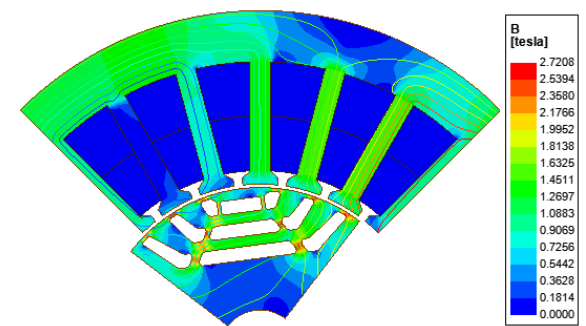

(b)

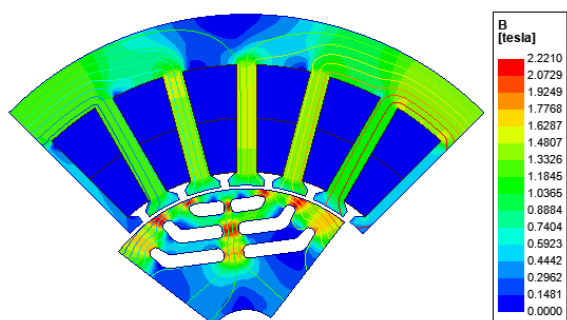

(c)

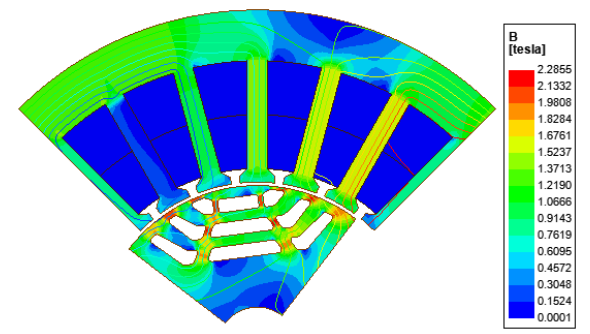

(d)

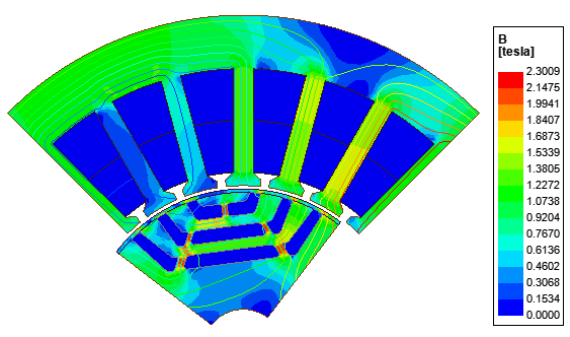

(e)

Fig. 1. Flux density at rated conditions for SynRel machine configuration (a) HS centre rib (b) HS side rib (c) centre rib (d) side rib (e) sleeve rotor

TABLE I

TARGET SPECIFICATIONS OF THE SYNREL MACHINE

\begin{tabular}{cc}
\hline \hline Rated Speed (krpm) & 60 \\
Rated Torque (Nm) & 0.6 \\
Maximum outer diameter of stator (mm) & 100 \\
Maximum stack length (mm) & 30 \\
DC link voltage (V) & 620 \\
\hline
\end{tabular}

TABLE II

IMPORTANT PARAMETERS OF THE SYNREL MACHINE

\begin{tabular}{cc}
\hline \hline Parameter & Value \\
\hline Stator outer diameter $(\mathrm{mm})$ & 100 \\
Stack length $(\mathrm{mm})$ & 30 \\
Pole pairs & 2 \\
Peripheral speed $(\mathrm{m} / \mathrm{s})$ & 150 \\
Slots/pole/phase & 2 \\
\hline \hline
\end{tabular}

from being nullified by the rotor inertia. Based on this, the target specification for the high speed SynRel machine is drawn as given in Table I. The SynRel machine is expected to deliver a maximum output torque of $0.6 \mathrm{Nm}$ from 0 to $60 \mathrm{krpm}$. The dimensional envelope is derived in terms of maximum stator outer diameter and stack length as given in Table I. Finally, it is essential to select the materials and incorporate structural simplifications necessary to reduce the cost and complexity involved in the fabrication of the SynRel machine for an EAT.

\section{ROTOR WITH HIGH STRENGTH LAMINATION}

Electric machines with a peripheral speed greater than $150 \mathrm{~m} / \mathrm{s}$ are classified as high speed machines. The SynRel machine is designed by considering a peripheral speed of $150 \mathrm{~m} / \mathrm{s}$ and the resulting parameters are shown in Table. II.
TABLE III

SIMULATION RESULTS OF PRELIMINARY DESIGNS

\begin{tabular}{ccccc}
\hline \hline Topology & $\begin{array}{c}\text { Torque } \\
(\mathrm{Nm})\end{array}$ & $\begin{array}{c}\text { Torque } \\
\text { ripple } \\
(\%)\end{array}$ & $\begin{array}{c}\text { Maximum } \\
\text { stress in rotor } \\
\text { lamination } \\
(\mathrm{MPa})\end{array}$ & $\begin{array}{c}\text { Maximum } \\
\text { stress in } \\
\text { sleeve } \\
(\mathrm{MPa})\end{array}$ \\
\hline HS Center Rib & 0.610 & 50.32 & 710.3 & - \\
HS Side Rib & 0.734 & 12.94 & 697.4 & - \\
Center Rib & 0.077 & 305.51 & 390.4 & - \\
Side Rib & 0.510 & 43.65 & 384.2 & - \\
Sleeve Rotor & 0.830 & 20.60 & 388.0 & 983.3 \\
\hline \hline
\end{tabular}

TABLE IV

MATERIAL PARAMETER FOR STRESS ANALYSIS

\begin{tabular}{cccc}
\hline \hline Material & $\begin{array}{c}\text { Density } \\
\left(\mathrm{kg} / \mathrm{m}^{3}\right)\end{array}$ & $\begin{array}{c}\text { Poisson's } \\
\text { ratio }\end{array}$ & $\begin{array}{c}\text { Young's } \\
\text { modulus }(\mathrm{GPa})\end{array}$ \\
\hline Lamination & 7650 & 0.3 & 210 \\
Sleeve & 7800 & 0.272 & 197 \\
Meldin & 1500 & 0.24 & 10 \\
\hline \hline
\end{tabular}

The thickness of all flux barriers and rotor islands are set equally to $1.5 \mathrm{~mm}$ and $2 \mathrm{~mm}$, respectively. In addition, the ends of the flux barrier are positioned equidistant from each other. Conventionally, a high speed SynRel machine is designed with high strength rotor lamination to reduce the rib thickness and thereby, increase the saliency ratio. Iron ribs are generally classified into radial, tangential and side ribs. Radial ribs are positioned along the q-axis of a SynRel machine. Tangential ribs are the ones present adjacent to the airgap. Finally, the side ribs are intermediately placed between the radial and tangential ribs. $\mathrm{d}$ and $\mathrm{q}$-axis represent the easy and hard direction of magnetization, respectively.

HS centre rib refers to the SynRel rotor configuration having both radial and tangential ribs, and using high strength lamina- 


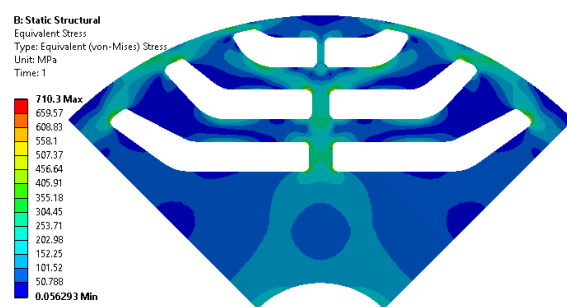

(a)

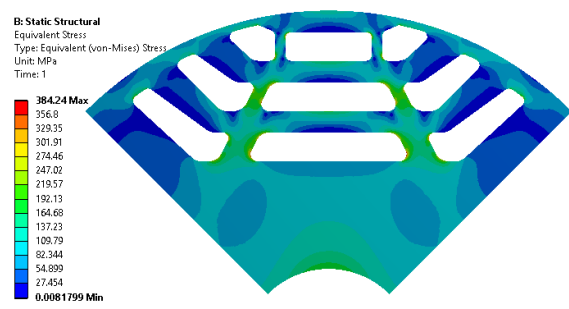

(d)

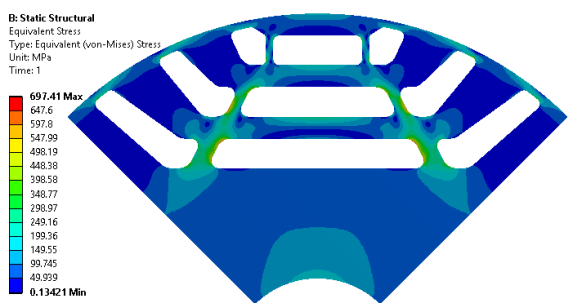

(b)

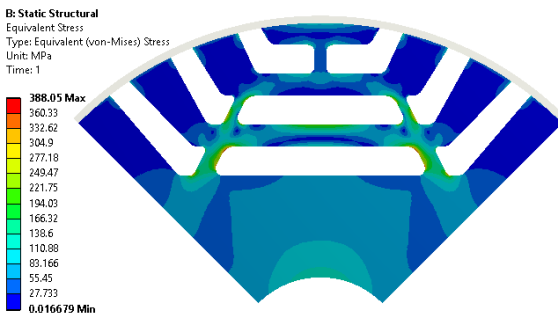

(e)

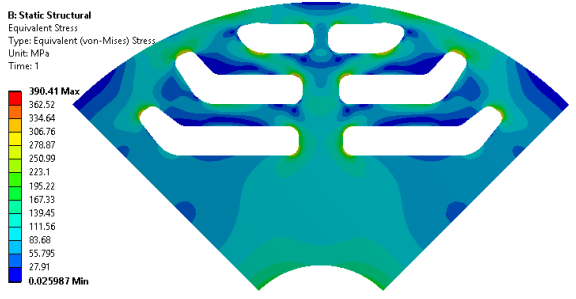

(c)

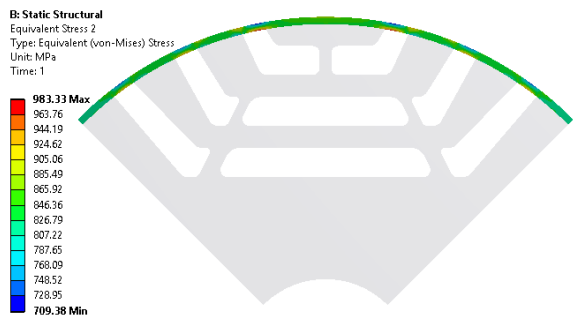

(f)

Fig. 2. Von-Mises stress at $66 \mathrm{krpm}$ for SynRel machine configuration (a) HS centre rib (b) HS side rib (c) centre rib (d) side rib (e) sleeve rotor: lamination (f) sleeve rotor: sleeve

tion. Similarly, the topology with side and tangential ribs and using high strength lamination is called HS side rib. The flux density at rated conditions with maximum torque per ampere operation for HS center rib and HS side rib configurations are shown in Figs. 1(a) and 1(b), respectively. The electromagnetic performance in terms of torque and torque ripple for both HS centre rib and HS side rib are shown in Table III. The output torque obtained from both the configurations using high strength lamination are found to satisfy the specification provided in Table I.

A high strength lamination with an yield strength of $860 \mathrm{MPa}$ is considered in our analysis. The maximum allowable stress in the high strength rotor lamination is fixed at $720 \mathrm{MPa}$ by incorporating a safety factor of 1.2. Static structural analysis is performed at $66 \mathrm{krpm}$ by considering a safety factor of 1.1 on the maximum speed to analyse the induced stress in the rotor lamination. The value of maximum Von-Mises stress in HS center rib and HS side rib are obtained from Figs. 2(a) and 2(b) respectively and shown in Table III. The maximum Von-Mises stress is below $720 \mathrm{MPa}$ is both the configurations. Therefore, HS centre rib and HS side rib satisfy both electromagnetic and mechanical requirements. Nonetheless, the target specification is satisfied by using relatively expensive high strength rotor lamination.

\section{ROTOR WITH LOW STRENGTH LAMINATION}

In this section, the high speed SynRel machine is designed and analysed with the conventional low strength lamination. The thickness of flux barriers, thickness of rotor islands and the position of flux barrier ends remain unaltered from that of SynRel machines with high strength lamination as discussed in Section III. Centre rib refers to the SynRel rotor configuration having both radial and tangential ribs, and using low strength lamination. Similarly, the topology with side and tangential ribs and using low strength lamination is called side rib.
The flux density at rated conditions with maximum torque per ampere operation for center rib and side rib configurations are shown in Figs. 1(c) and 1(d), respectively. The electromagnetic performance in terms of torque and torque ripple for both centre rib and side rib are shown in Table III. The output torque obtained from these configurations are below the specification provided in Table I.

The conventional lamination has an yield strength of $480 \mathrm{MPa}$. The maximum allowable stress in the rotor lamination is fixed at $400 \mathrm{MPa}$ by incorporating a safety factor of 1.2. The value of maximum Von-Mises stress in center rib and side rib configurations at $66 \mathrm{krpm}$ are obtained from Figs. 2(c) and 2(d), respectively and shown in Table III. The maximum Von-Mises stress is below $400 \mathrm{MPa}$ is both the configurations. Therefore, both centre and side rib configurations satisfy the mechanical requirements. The inferior electromagnetic performance obtained with the conventional lamination favours the development of alternative low-priced rotor topologies for being employed in high speed SynRel machines.

\section{ROTOR WITH HIGH STRENGTH MARTENSITIC SLEEVE}

Conventional sleeve rotor SynRel machine comprises of low strength magnetic lamination retained by non magnetic retaining sleeve. The magnetic islands in the rotor are not connected with iron ribs. Therefore, the rotor islands are isolated. This adds to the complexity of fabrication and also increases the burden on the retaining sleeve with the need to handle the entire mechanical stress. In addition, the apparent air gap increases due to the non magnetic nature of the retaining sleeve. The power factor of the SynRel machine is adversely affected by the increase in airgap. Consequently, in this section, a sleeve rotor SynRel machine with martensitic retaining sleeve is studied. Majority of the martensitic materials, including the one considered in our analysis, are magnetic in nature. Hence, there is no increase in airgap. Besides this, the 


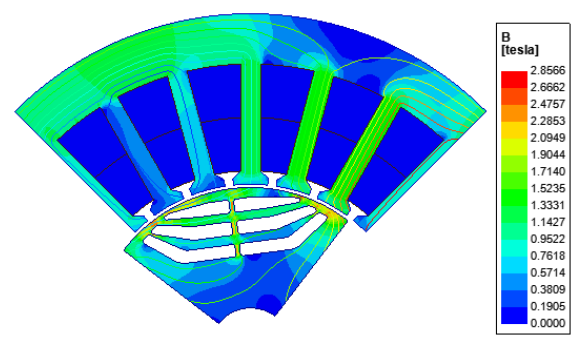

(a)

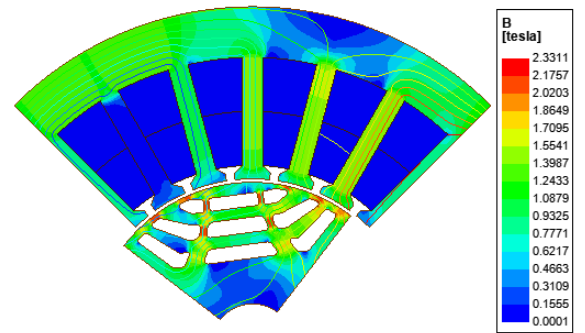

(d)

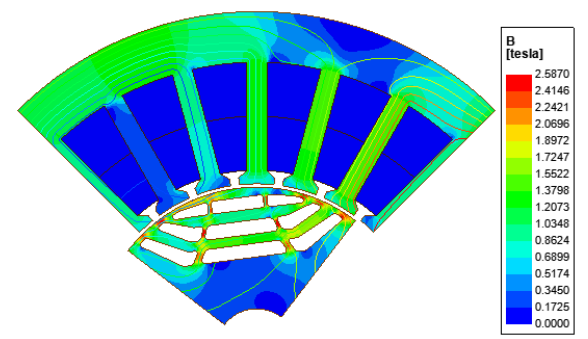

(b)

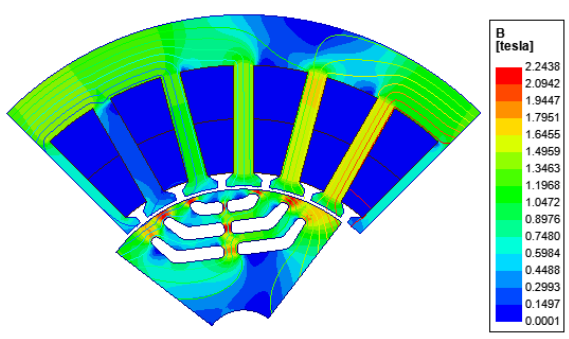

(c)
TABLE V

SIMULATION RESULTS OF OPTIMIZED DESIGNS

\begin{tabular}{ccccc}
\hline \hline Topology & $\begin{array}{c}\text { Torque } \\
(\mathrm{Nm})\end{array}$ & $\begin{array}{c}\text { Torque } \\
\text { ripple } \\
(\%)\end{array}$ & $\begin{array}{c}\text { Maximum } \\
\text { stress in rotor } \\
\text { lamination } \\
(\mathrm{MPa})\end{array}$ & $\begin{array}{c}\text { Maximum } \\
\text { stress in } \\
\text { sleeve } \\
(\mathrm{MPa})\end{array}$ \\
\hline HS Center Rib & 0.875 & 18.82 & 717.2 & - \\
HS Side Rib & 0.821 & 14.71 & 665.2 & - \\
Center Rib & 0.422 & 19.24 & 399.8 & - \\
Side Rib & 0.624 & 17.69 & 399.3 & - \\
Sleeve Rotor & 0.915 & 10.51 & 358.5 & 991.2 \\
\hline \hline
\end{tabular}

rotor islands are connected with iron ribs to ease the process of fabrication. Simultaneous reduction of the sleeve and iron rib thickness are essential to improve the overall performance of the sleeve rotor SynRel machine.

The thickness of flux barriers, thickness of rotor islands and the position of flux barrier ends remain unaltered from that of the SynRel machines with high strength lamination as discussed in Section III. The thickness of the retaining sleeve is fixed at $0.5 \mathrm{~mm}$. The sleeve rotor configuration considered in our analysis comprises of a radial rib in flux barrier 1 while side ribs in barriers 2 and 3. Th electromagnetic analysis is performed by including the effects of eddy current induced in the retaining sleeve. The flux density at rated conditions with maximum torque per ampere operation for the sleeve rotor configuration is shown in Fig. 1(e). The electromagnetic performance in terms of torque and torque ripple are shown in Table III. The output torque is found to satisfy the specification provided in Table I.

The martensitic sleeve has an yield strength of $1200 \mathrm{MPa}$. The maximum allowable stress in the retaining sleeve is fixed at $1000 \mathrm{MPa}$ by incorporating a safety factor of 1.2. An interference fit is established between the rotor lamination and the retaining sleeve. The value of maximum Von-Mises stress in the conventional lamination and the retaining sleeve for the sleeve rotor configurations at $66 \mathrm{krpm}$ are obtained from Figs. 2(e) and 2(f), respectively and shown in Table III. The maximum Von-Mises stress is below $400 \mathrm{MPa}$ and $1000 \mathrm{MPa}$ in the lamination and the retaining sleeve, respectively. Therefore, the sleeve rotor configuration satisfies both electromagnetic and mechanical requirements. Additionally, the sleeve rotor configuration enables the utilization of conventional low yield strength lamination.

\section{MULTIPHYSICS OPTIMIZATION}

Based on the output from the preliminary designs, as shown in Table III, the sleeve rotor SynRel machine configuration is found to outperform its counterparts. However, the complicated rotor structure of the SynRel machine necessitates a multiphysics optimization to validate the superiority of sleeve rotor SynRel machine. The saliency of a SynRel machine is the ratio of $d$ and $q$ axis inductance. The $d$ axis inductance $\left(L_{d}\right)$ is highly influenced by the thickness of rotor islands. Similarly, the value of $\mathrm{q}$ axis inductance $\left(\mathrm{L}_{\mathrm{q}}\right)$ depends heavily on the thickness of iron ribs and the flux barriers. Therefore, torque maximization requires the thickness of iron ribs, flux barriers and rotor islands to be optimized. Likewise, the minimization of torque ripple involves the optimization of flux barrier ends. Consequently, a multiphysics optimization, comprising both electromagnetic and structural analysis is performed on all the rotor configurations and the results are shown in Table V. In addition, the stator structure is maintained same to ease the comparison of different rotor configurations.

The flux density at rated conditions with maximum torque per ampere operation for HS centre rib, HS side rib, centre rib, side rib and sleeve rotor are shown in Figs. 3(a), 3(b), 3(c), $3(\mathrm{~d})$ and 3(e), respectively. The electromagnetic performance 


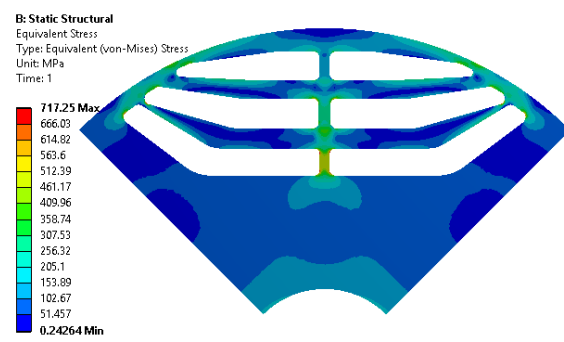

(a)

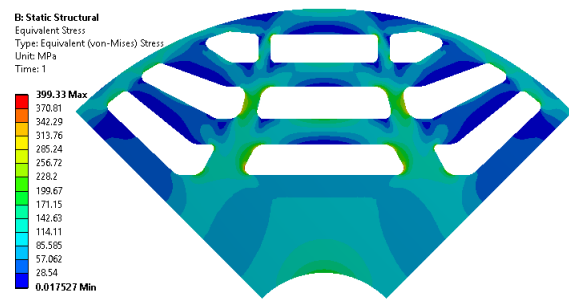

(d)

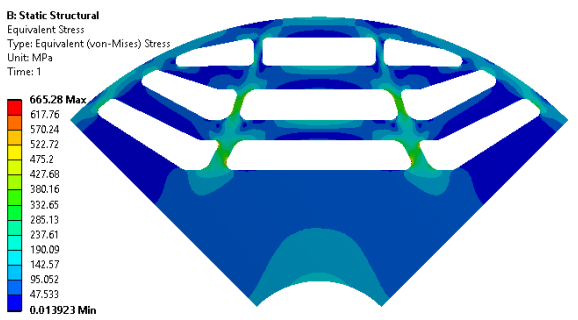

(b)

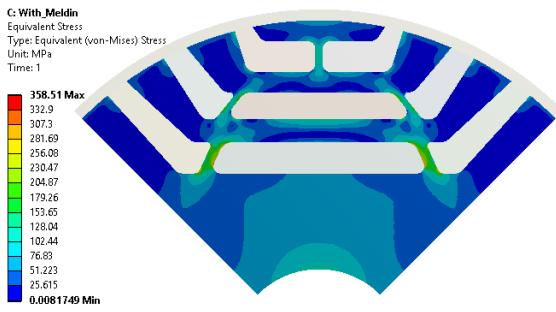

(e)

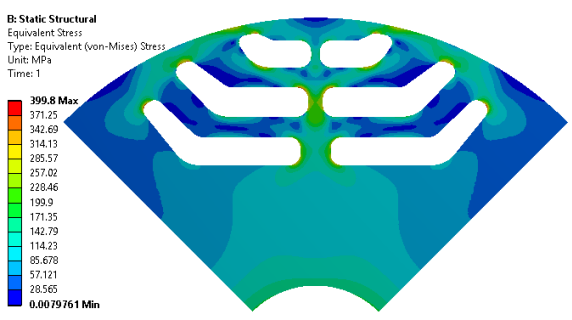

(c)

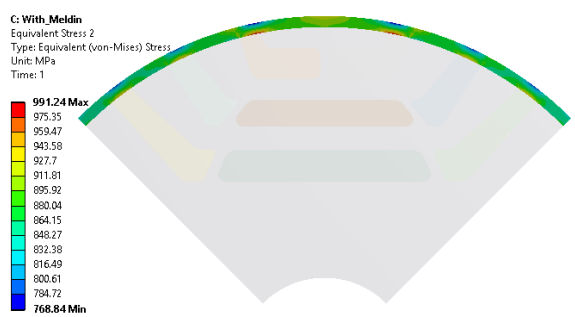

(f)

Fig. 4. Von-Mises stress at $66 \mathrm{krpm}$ for optimized SynRel machine configuration (a) HS centre rib (b) HS side rib (c) centre rib (d) side rib (e) sleeve rotor: lamination (f) sleeve rotor: sleeve

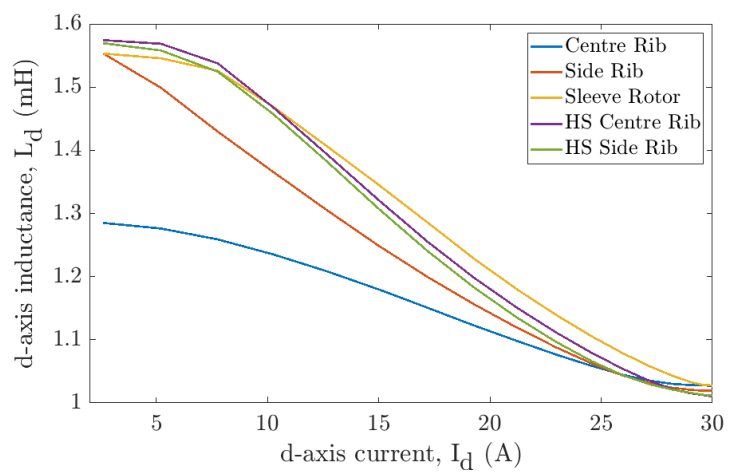

(a)

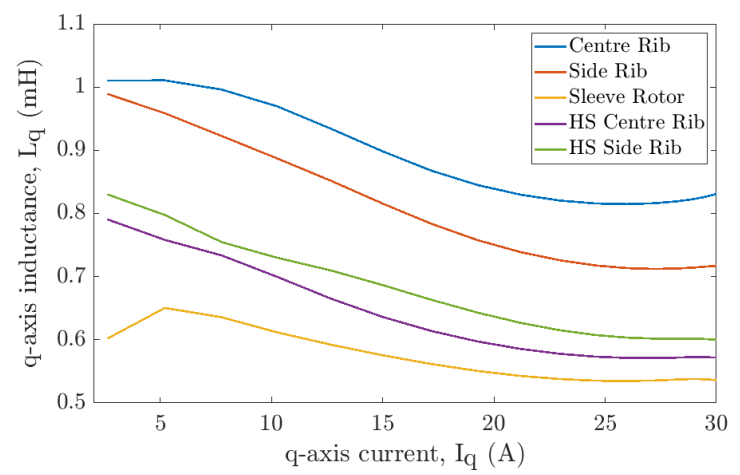

(b)

Fig. 5. Comparison of all the optimized SynRel machine configurations based on the variation of (a) $L_{d}$ w.r.t $I_{d}$ (b) $L_{q}$ w.r.t $I_{q}$

in terms of torque and torque ripple for all the optimized rotor configurations are listed in Table V. The output torque is found to satisfy the specification given in Table I for all the configurations except centre rib. In addition, an improvement is noticed on the output torque of all the optimized rotor configurations as shown in Table $\mathrm{V}$ in comparison to the performance of their respective preliminary models as given in Table IV. Similarly, the torque ripple is also reduced for all the optimized configurations except HS side rib.

The value of maximum Von-Mises stress in HS centre rib, HS side rib, centre rib, side rib, lamination of sleeve rotor and retaining sleeve of sleeve rotor at $66 \mathrm{krpm}$ are obtained from Figs. 4(a), 4(b), 4(c), 4(d), 4(e), and 4(f), respectively and shown in Table V. The maximum Von-Mises stress is below $720 \mathrm{MPa}$ in HS centre rib and HS side rib. Similarly, the maximum Von-Mises stress is below $400 \mathrm{MPa}$ in centre rib, side rib and lamination of sleeve rotor configurations. Finally, the high strength martensitic sleeve present in the sleeve rotor configuration also exhibits a maximum Von-Mises stress below $1000 \mathrm{MPa}$. Therefore, all rotor configurations except centre rib satisfies both electromagnetic and mechanical performance. In addition, the sleeve rotor is found to out perform other configurations in terms of both torque and torque ripple. $4.5 \%$, $11.4 \%, 116.9 \%$ and $46.7 \%$ of more torque is obtained from sleeve rotor in comparison to HS centre rib, HS side rib, centre rib and side rib. Finally, the sleeve rotor SynRel machine configuration comprises $90.46 \%$ of conventional lamination in the rotor by volume.

\section{REASON BEHIND THE SUPERIOR PERFORMANCE OF SLEEVE ROTOR SYNREL MACHINE}

The variation of $\mathrm{L}_{\mathrm{d}}$ and $\mathrm{L}_{\mathrm{q}}$ at the rated operating conditions for all the optimized rotor configurations are shown in Figs. 5(a) and 5(b), respectively. It is observed that the influence of rotor configuration is more pronounced on $L_{d}$ than that of $\mathrm{L}_{\mathrm{q}}$. It is possible to get better insights by comparing $\mathrm{L}_{\mathrm{d}}$ and $\mathrm{L}_{\mathrm{q}}$ of all the rotor configurations w.r.t the corresponding inductance of centre rib as shown in Figs. 6(a) and 6(b), respectively. Maximizing the output torque is the most important constraint while optimizing the electric machine for an EAT. 


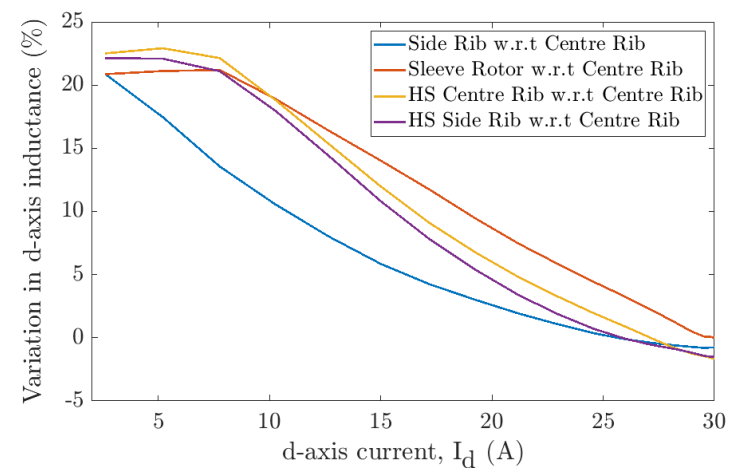

(a)

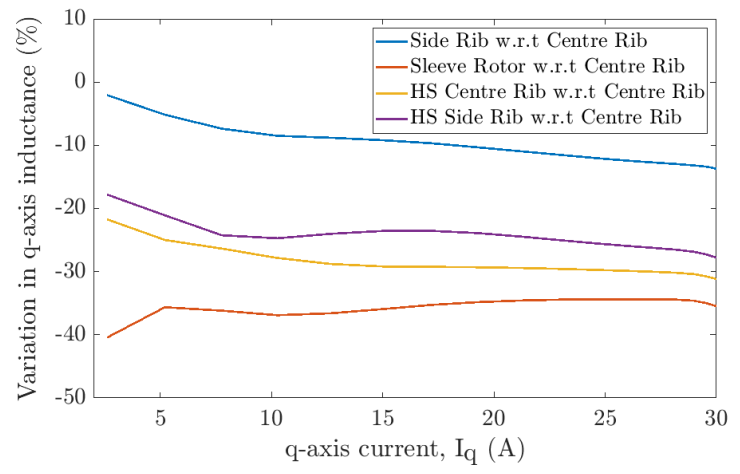

(b)

Fig. 6. Variation of inductance for all the optimized rotor configurations w.r.t center rib along (a) d-axis (b) q-axis

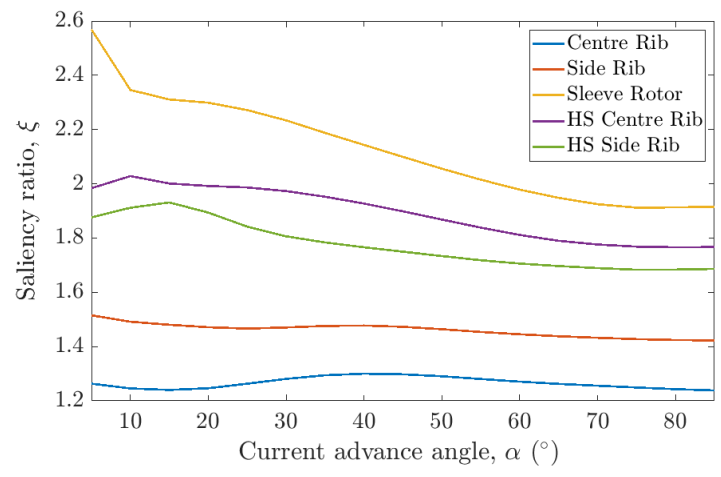

Fig. 7. Comparison of all the optimized SynRel machine configurations based on variation of saliency w.r.t current advance angle

Consequently, the inferior torque density offered by the centre rib SynRel machine configuration necessitates improvement and validates its choice as the benchmark configurations.

The improvement in $\mathrm{L}_{\mathrm{d}}$ for all the rotor configurations w.r.t the center rib is nearly same as shown Fig. 6(a). In contrast, the reduction in $\mathrm{L}_{\mathrm{q}}$ w.r.t the centre rib as shown in Fig. 6(b) is found to have a close correlation with the output torque, namely, sleeve rotor $>$ HS side rib $>$ HS centre rib $>$ side rib $>$ centre rib. Finally, for completeness, the saliency ratio of all rotor configurations are shown in Fig. 7.

\section{CONCLUSION}

Simple, rugged and magnet less configurations of electric machines which offer high torque density are required in EATs. Based on this, a $3.5 \mathrm{~kW}, 60 \mathrm{krpm}$ martensitic sleeve rotor SynRel machine is introduced in this paper. A multiphysics optimization, including both electromagnetic and structural analysis, is performed to ascertain the superiority of the high speed sleeve rotor configuration. The major outcomes of this research are as follows:

- The sleeve rotor configuration is found to exhibit superior electromagnetic performance in terms of both torque and torque ripple compared to conventional SynRel machines using both low and high strength lamination.
- $4.5 \%, 11.4 \%, 116.9 \%$ and $46.7 \%$ of more torque is obtained from sleeve rotor in comparison to HS centre rib, HS side rib, centre rib and side rib.

- The sleeve rotor configuration comprises $90.46 \%$ of conventional lamination in the rotor by volume.

- The presence of iron ribs decreases the complexity and thereby, reduces the cost of fabrication.

\section{REFERENCES}

[1] Automotive Council, UK, "The roadmap report-towards 2040: A guide to automotive propulsion technologies," 2018.

[2] H. Wu, G. Alberts, J. Hopper, and B. Walton, "New market. new entrants. new challenges. battery electric vehicles," Deloitte LLP, London, UK, 2019.

[3] C. D. Rakopoulos and E. G. Giakoumis, Diesel engine transient operation: principles of operation and simulation analysis. Springer Science \& Business Media, 2009.

[4] W. Lee, E. Schubert, Y. Li, S. Li, D. Bobba, and B. Sarlioglu, "Overview of electric turbocharger and supercharger for downsized internal combustion engines," IEEE Transactions on Transportation Electrification, vol. 3, no. 1, pp. 36-47, 2017.

[5] D. Gerada, Z. Xu, X. Huang, and C. Gerada, "Fully-integrated highspeed im for improving high-power marine engines," IET Electric Power Applications, vol. 13, no. 2, pp. 148-153, 2019.

[6] M. Lim, J. Kim, Y. Hwang, and J. Hong, "Design of an ultra-high-speed permanent-magnet motor for an electric turbocharger considering speed response characteristics," IEEE/ASME Transactions on Mechatronics, vol. 22, no. 2, pp. 774-784, 2017.

[7] D. Gerada, X. Huang, C. Zhang, H. Zhang, X. Zhang, and C. Gerada, "Electrical machines for automotive electrically assisted turbocharging," IEEE/ASME Transactions on Mechatronics, vol. 23, no. 5, pp. 2054 2065,2018

[8] C. Babetto, G. Bacco, and N. Bianchi, "Synchronous reluctance machine optimization for high-speed applications," IEEE Transactions on Energy Conversion, vol. 33, no. 3, pp. 1266-1273, 2018.

[9] J. Ahn, C. Han, C. Kim, and J. Choi, "Rotor design of high-speed permanent magnet synchronous motors considering rotor magnet and sleeve materials," IEEE Transactions on Applied Superconductivity, vol. 28 , no. 3, pp. 1-4, 2018.

[10] P. B. Reddy, K. Grace, and A. El-Refaie, "Conceptual design of sleeve rotor synchronous reluctance motor for traction applications," in 2015 IEEE International Electric Machines Drives Conference (IEMDC), 2015, pp. 195-201.

[11] K. Grace, S. Galioto, K. Bodla, and A. M. El-Refaie, "Design and testing of a carbon-fiber-wrapped synchronous reluctance traction motor," IEEE Transactions on Industry Applications, vol. 54, no. 5, pp. 4207-4217, 2018.

[12] N. Bianchi and B. J. Chalmers, "Axially laminated reluctance motor: analytical and finite-element methods for magnetic analysis," IEEE Transactions on Magnetics, vol. 38, no. 1, pp. 239-245, 2002. 